\title{
5-alpha-reductase deficiency: a case report
}

\author{
Diana Mettadewi Jong, MD; Aman B Pulungan, MD; Bambang Tridjaja AAP, MD; \\ Jose RL Batubara, MD
}

$\Gamma$

he condition of 5-alpha-reductase type 2 deficiency (5-ARD) is an inherited disorder resulting in the inability to convert testosterone to dihydrotestosterone (DHT). ${ }^{1-4}$ This disorder was previously termed as familial incomplete male pseudohermaphroditism type 2 , pseudovaginal perineoscrotal hypospadias. ${ }^{1,2}$ Clinical manifestation of 5-ARD is limited to male genetic. ${ }^{1-4}$ The affected males are usually identified as female in childhood but undergo striking virilization at puberty. 2,3

While overall incidence for various countries are not established, increased incidence is reported in the Dominican Republic, some highland tribes in New Guinea, Lebanon and Turkey. ${ }^{5-8}$ This was the first documented case in Cipto Mangunkusumo (CM) Hospital.

\section{Report of the case}

An 18 year-old "girl" teenager was referred to Pediatric Endocrinology Clinic CM hospital by The Plastic Surgery Department CM Hospital with perineoscrotal hypospadia, micropenis, and complete testes. The patient was raised as a girl at birth until 12 years old when the parents noted a penis at the patient's genital. By the age of 14 , the patient's voice had begun to deepen. The patient was noted to have no breast development and failure to menstruate.

History of pregnancy and delivery were normal. The patient preferred male activities as a child, such as playing kites, climbing trees instead of playing dolls. By the age of 15, the patient started to be attracted to girls and was aware of the difference from other girls.

The patient was the second child of four siblings. There was no consanguinity in the family. The patient had a "sister", 7 years old, who had similar appearance with the patient. Chromosomal analysis of the "sister" revealed male chromosome. No history of this disorder was found in the rest of the family.

Physical examination showed that the patient was alert. Vital signs were in normal limits. Body weight was $53 \mathrm{~kg}\left(<\mathrm{P}_{3} \mathrm{NCHS}\right)$, and height was $156 \mathrm{~cm}\left(<\mathrm{P}_{3} \mathrm{NCHS}\right)$. Potential genetic height was between $155 \mathrm{~cm}$ and $172 \mathrm{~cm}$. No dysmorphism was noted, no mustache was seen, the voice was deepened and Adam's apple was prominent. The shoulders were relatively broad, no breast enlargement was seen. The urethra orifice was found at the perineoscrotal region, phallus length was $4 \mathrm{~cm}(11,0$ $\pm 1,1 \mathrm{~cm}$, mean $2,5 \mathrm{SD} 8,3 \mathrm{~cm}$ ), gonads volume were $8 \mathrm{ml} / 8 \mathrm{ml}$, and a bifid scrotum with rugae was seen. The Prader stage was 3. Puberty state was A3P4G4.

Chromosomal analysis revealed 46, XY. Before performing hCG test, testosterone level was $633 \mathrm{ng} /$

From the Department of Child Health, Medical School, University of Indonesia, Cipto Mangunkusumo Hospital, Jakarta.

Reprint requests to: Diana M. Jong, MD, Department of Child Health, Medical School, University of Indonesia, Jakarta, Indonesia. Tel.62-21. 3907740, Fax. 62-21-3907743. 


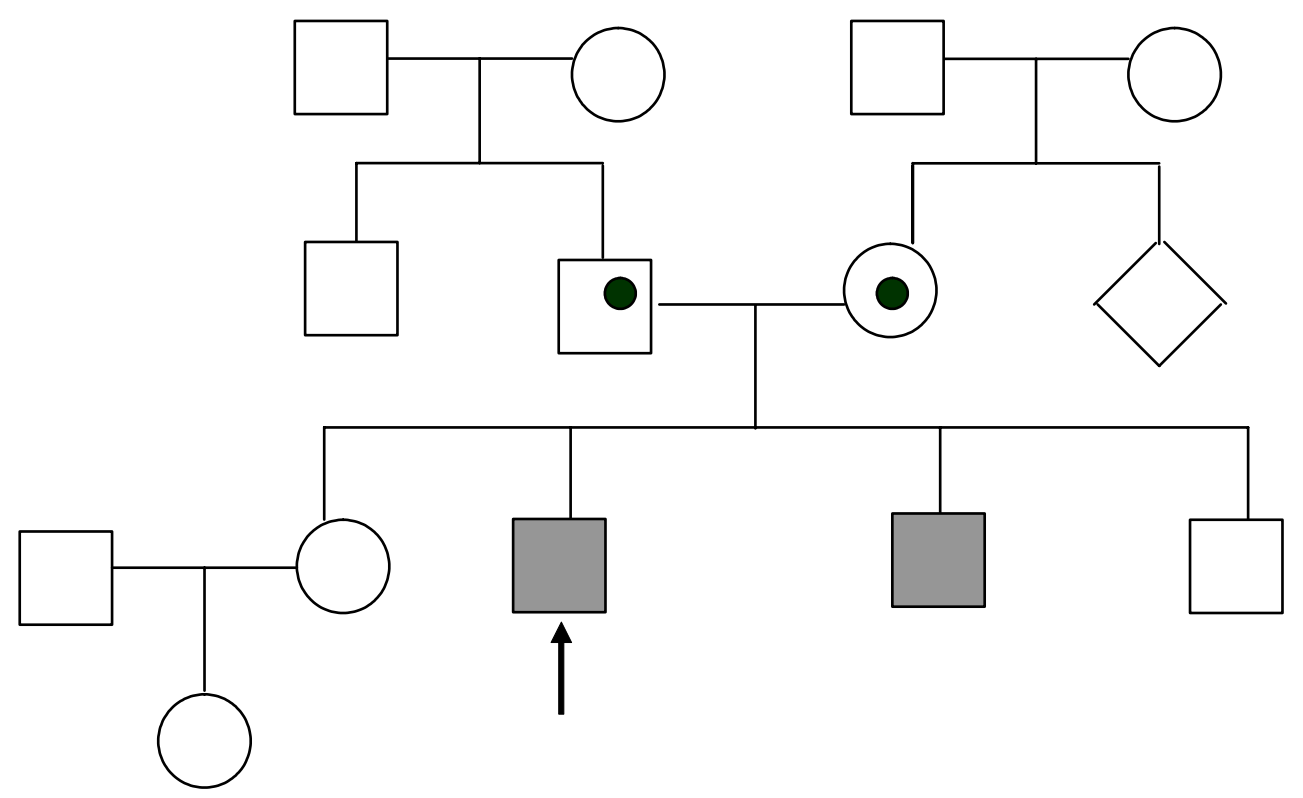

Figure 1. Pedigree of the family

dl (normal: 284.2 - $946.6 \mathrm{ng} / \mathrm{dl}$ ) and dihydrotestosterone level was $14 \mathrm{ng} / \mathrm{dl}$ (normal: 30 - $85 \mathrm{ng} / \mathrm{dl}$ ). After hCG test, testosterone level increased to $752 \mathrm{ng} / \mathrm{dl}$ and dihydrotestosterone level decreased to $12 \mathrm{ng} / \mathrm{dl}$. Testosterone to dihydrotestosterone ratio was 63:1. Bone age revealed average boy (Greulich-Pyle standard). Abdominal ultrasound revealed the absence of uterus.

The diagnosis of this patient was 5-alpha-reductase deficiency. The parents were informed about this disorder. The patient and family were consulted to a child psychiatrist. Psychological evaluation revealed that the patient adopted male identity. Treatment with $50 \mathrm{mg}$ testosterone per dose given intramuscularly, 4 times, in 3 weeks interval was started. External genitalia reconstruction was planned to perform after hormonal treatment. Psychosocial support was started as soon as the diagnosis was established. After the third dose of testosterone therapy, the penis length showed no improvement, so the dose of testosterone was increased to $250 \mathrm{mg}$ per dose with 4-week interval.

\section{Discussion}

The differentiation of genital ducts begins around the fourth week of gestation when the Wolffian ducts develop. The presence of fetal testis determines further direction of genital duct differentiation in male. ${ }^{9,10}$ (Figure 2)

5-ARD is an autosomal recessive sex-linked condition resulting in the inability to convert testosterone to the more physiologically active DHT. Since DHT is required for the normal masculinization of the external genitalia in utero, genetic males with 5ARD are born with ambiguous genitalia. They are usually identified as female at birth, 2,3,10,11 as in this case.

The described clinical abnormalities range from infertility with normal male genital anatomy to underdeveloped male with hypospadias to predominantly female external genitalia, most often with mild clitoromegaly. ${ }^{2,12}$ Phenotypic findings in a newborn are limited to the genitalia. Most commonly, the external genitalia exhibit labial appearance to the labioscrotal folds with some mild rugation or pigmentation, clitoris-like phallus, perineoscrotal hypospadia, and pseudovagina blind ending introitus. The testes are usually in the inguinal canals bilaterally; however, in some individuals with 5-ARD, the testes can be found in the labioscrotal folds or retained in the abdomen. Clear signs of virilization predominate at puberty. The phallus exhibits definite enlargement. The shoulders are relatively broad and the hips are narrow, muscularity may increase, and generally no 


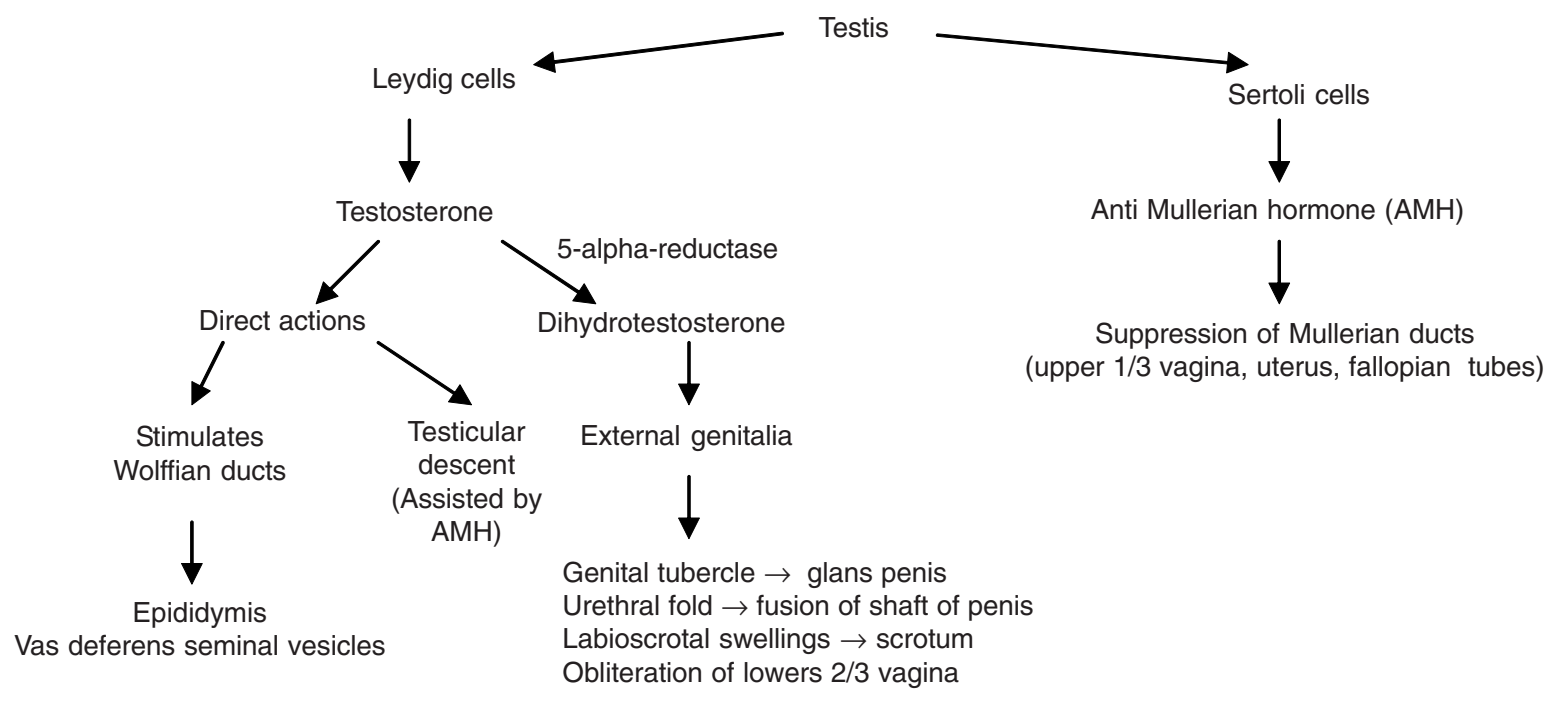

Figure. 2. The process of sexual differentiation. ${ }^{9}$

breast development. A prominent Adam's apple may start to develop, scanty hair usually presents, and the voice may begin to deepen. The uterus and fallopian tubes are absent due to the normal secretion of the Müllerian-inhibiting factor. Testes are intact, as are wolffian structures such as epididymis, vas deferens, and seminal vesicles. ${ }^{1,2,11,13}$ In this case, the patient came at late puberty (A3P4G4) with perineoscrotal hypospadia, bifid scrotum, micropenis, intact testes, and the absence of uterus.

A deficiency of the type 2 of isozyme 5-alphareductase, which transforms testosterone to DHT, is the root cause of this disorder. ${ }^{1,2,13}$ Two genes coding for 5-alpha-reductase have been identified, each for a slightly different isoenzyme. ${ }^{2,14}$ The gene for 5-alpha-reductase type 1 has been determined to be on chromosome 5. Its product is expressed only after birth. ${ }^{2,13,15-17}$ Linkage analysis has demonstrated that the type-1 enzyme is unrelated to the clinical syndrome of 5-ARD. The other isoenzyme, 5-alpha reductase type 2 (SRD5A2), determined on chromosome 2, correlates with clinical symptoms. It is expressed in high levels in the prostate and other androgen-sensitive tissues. More than 20 different mutations of this gene have been reported in people with clinical and biochemical evidence of this enzyme deficiency. 2,6-8,13,15-18 Interestingly, partial virilization of males with 5 -ARD occurs at puberty and may be attributable to the rise in type-1 enzyme activity at that time. ${ }^{16,17}$ Thus, DHT, the most potent androgen, is bound selectively to the androgen receptors in genital skin and fibroblasts, making its action necessary for the development of normal male genital anatomy in the fetus. ${ }^{1,2,13}$

Studies in the Dominican Republic, Turkey, New Guinea, Sweden, Brazil, Mexico, and the Middle East showed the mutation of SRD5A2 located at band 2p23 in 5-ARD. ${ }^{6-8,13,15-18}$ Chavez et al showed the evidence of uniparental disomy in 5 ARD and revealed an alternate mechanism whereby this enzymatic disorder can be derived from a single parent. ${ }^{19}$ There is no correlation between severity of the genetic defect and phenotype. ${ }^{3,13}$ DNA analysis was not done in this case.

The biochemical diagnosis is based on finding normal to modestly elevated serum testosterone level, low to undetectable serum DHT level, with markedly increased basal and especially, hCGstimulated testosterone to DHT ratio $(>17)$, and high ratio of urinary etiocholanolone to androsterone and $5 \mathrm{~b}$ to $5 \mathrm{a}$ cortisol metabolites, low activity of 5-alpha-reductase in fibroblast cultured from genital skin and positive mutation analysis of SRD5A2.3,4,12,20,21 Basal testosterone to DHT ratio in healthy prepubertal children is 3 , and at puberty is 12.22 The normal level of testosterone in 

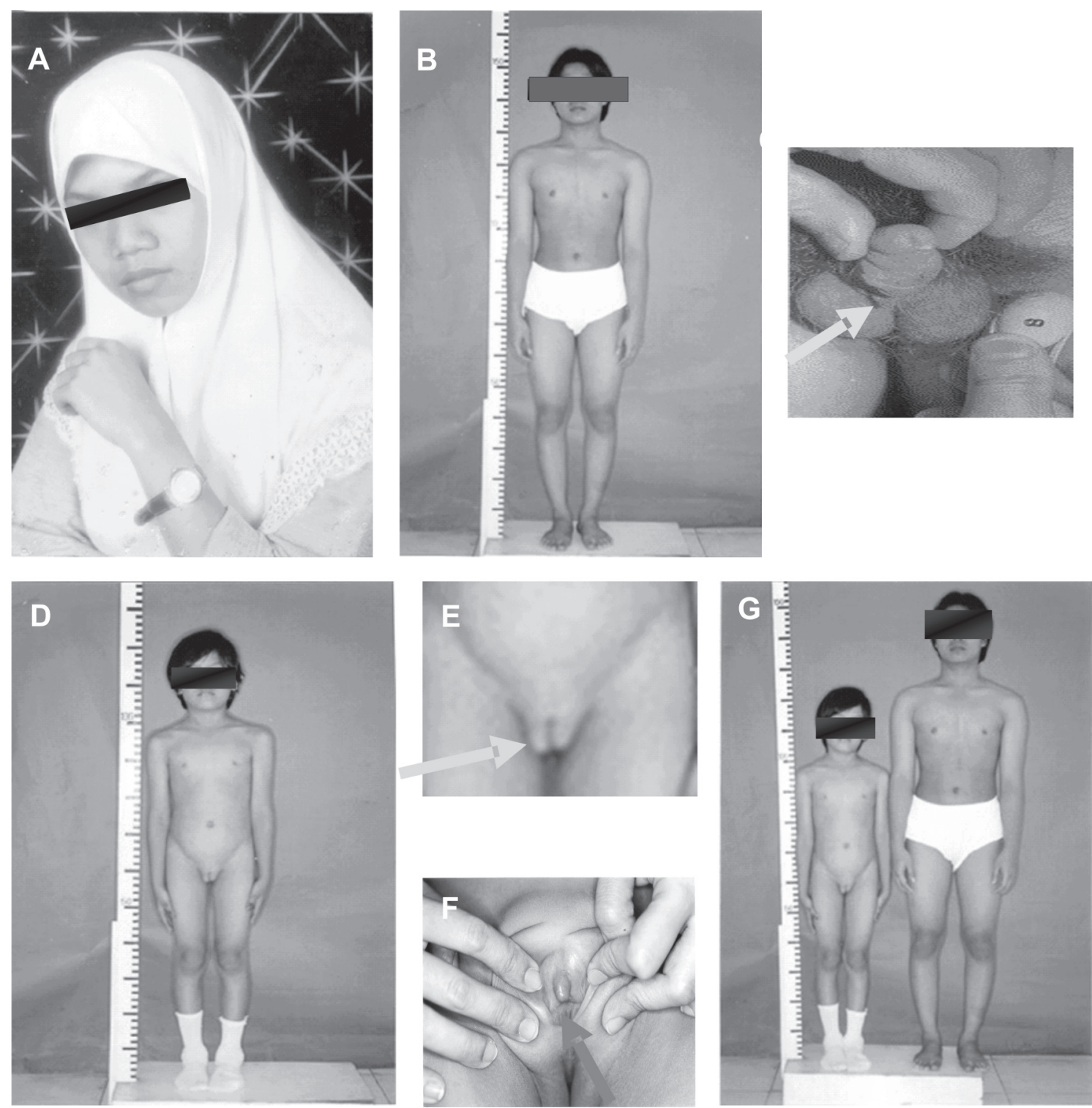

Figure 3. The patient before $(A) \&$ after $(B)$ changed his identity to male. Fig (C) A bifid scrotum with rugae, micropenis, \& perineoscrotal hypospadia (arrow) were found in physical examination of the patient. Fig (D) The patient's sister has the same condition as the patient. There were labioscrotal folds (arrow) (E) with testes in palpation, micropenis with perineoscrotal hypospadia (arrow) (F) found in physical examination of the sister. Fig $(G)$ The patient with his sister

this case, the low level of DHT, and hCG-stimulated testosterone to DHT ratio of $>17$ supported the diagnosis of 5-ARD.

Chromosomal analysis was performed to determine the genotype of the patient. ${ }^{2,13}$ Chromosomal analysis in this case revealed 46 XY. Abdominal ultrasound can verify the location of the testes and the absence of uterus. ${ }^{2}$ In this case, abdominal ultrasound showed the absence of uterus. If pseudovagina is found, a vaginogram is a useful tool to assess vaginal length and fistulous connections between the urinary tract and vagina. Histological findings in the testes exhibit leydig cell hyperplasia. However, testicular biopsy is not a part of the routine evaluation. ${ }^{2,13}$

Bone age is done to examine bone maturation. ${ }^{13}$ This patients was still in potential genetic height and his bone age revealed average boy. These showed the normal growth of the patient.

Diagnosis of 5-ARD is based on clinical findings, pedigree analysis, biochemical and radiological findings. $2,3,13,16,20,23$ No risk factor or any clinical marker in 

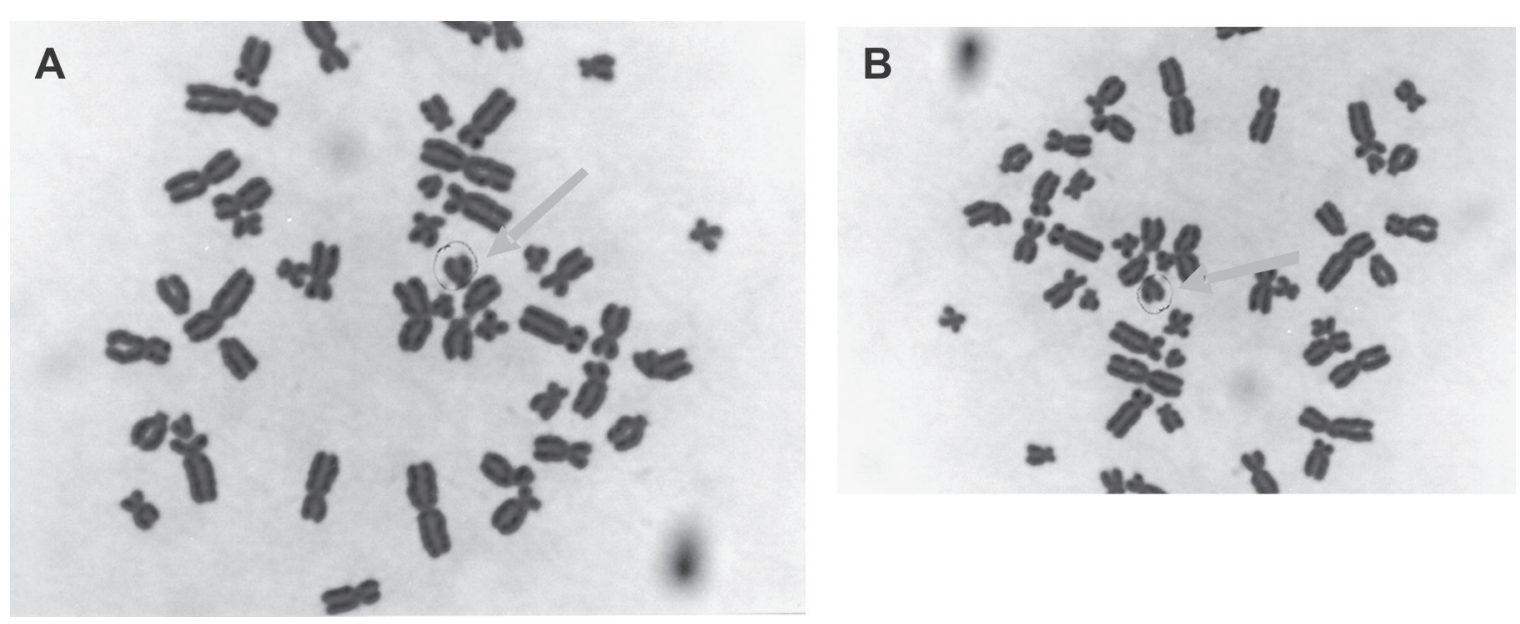

Figure 4. There were Y-chromosomes in the chromosomal analysis of the patient $(A)$ \& the sister (B)

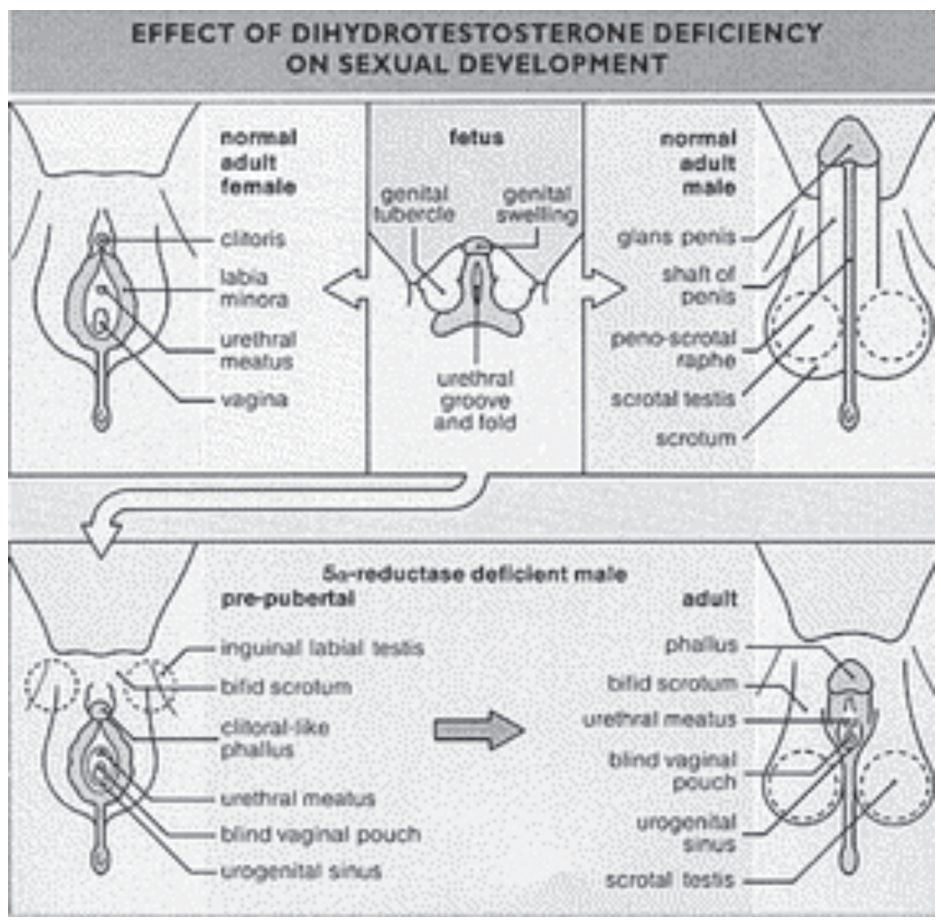

Figure 5. The effect of DHT deficiency on sexual development. ${ }^{1}$

pregnancy are known. Prenatal diagnosis with mutation analysis is rarely done in 5 -ARD. ${ }^{2}$ The diagnosis in this patient was established at late puberty, if it was performed earlier, the patient and family would be more prepared physically and psychologically, especially in gender transition.

The differential diagnosis of 5-ARD is partial androgen insensitivity syndrome (PAIS). The PAIS is an $\mathrm{X}$-linked disorder, in which partial virilization and gynaecomastia can be found at puberty. DHT level in PAIS is normal. 2,3

Management of 5-ARD is started with gender assignment. Almost all children with 5-ARD are assigned as female gender at birth. More than $70 \%$ of individuals with 5-ARD adopt male gender identity and male gender role at puberty. However, the remainders continue living in the female role and gender identity. 23-25 If the patient adopts male gender identity and 
micropenis is found, hormonal therapy with $2 \%$ of DHT cream should be immediately started. ${ }^{2,23}$ Some evidence suggests that high dose of 250-500 mg testosterone therapy or DHT may enhance virilization. ${ }^{23,26}$ Testosterone and DHT therapy are more effective to be administered before puberty. ${ }^{23}$ External genitalia reconstruction such as urethroplasty for hypospadia is done after hormonal therapy. ${ }^{1,23}$ In this patient, after psychological evaluation revealed male gender identity, high dose of testosterone therapy was administered at late puberty. DHT 2\% cream is still not available in Indonesia. Urethroplasty was planned to perform after hormonal therapy. If the patient adopts female gender identity, gonadectomy, genitoplasty, and hormone replacement therapy with estrogen are recommended. Estrogen is administered to stimulate secondary sex development and to prevent bone mineralization. ${ }^{2,23}$ Psychosocial support for the patient and family is important especially in gender transition. ${ }^{23-25} \mathrm{~A}$ multidisciplinary team approach, including pediatric endocrinologist, child psychiatrist, plastics surgeon or pediatric surgeon or pediatric urologist, and geneticist, is needed in diagnosis and management of 5-ARD. 2,23

5 -ARD is not life threatening; if intraabdominal testes are retained, an increased risk of gonadoblastoma exists. A risk of osteoporosis increases in gonadectomy without hormone replacement therapy. ${ }^{2} \mathrm{~A}$ deficiency in DHT production results in a highly viscous semen and an extremely low volume of ejaculate, although sperm counts may be normal; this may impair fertility. ${ }^{27}$ Katz et al described the use of intrauterine insemination with sperms from a man with this disorder and a history of infertility. The first pregnancy gave rise to a normal son and the second pregnancy produced fraternal twins. ${ }^{28}$ Psychological morbidity due to gender or sexual identity issues is usually complex. ${ }^{2}$ In this patient, cryptorchidism was not found and gonadectomy was not performed. So the risk of gonadoblastoma and osteoporosis may not exist. Psychological morbidity and infertility problem may occur in this patient's life.

\section{References}

1. Belchetz PE. The testis. In: Besser GM, Cudworth AG, editors. Clinical endocrinology. $1^{\text {st }}$ ed. Philadelphia: JB Lippincott; 1987. p. 1-18.
2. Wilson BE. 5-alpha-reductase deficiency. eMed J [serial online] 2001 July [cited 2002 July 15]; 2(7):[10 sections]. Available from: URL: http:// www.eMedicine.com/PED/topic 1980.html

3. Rapaport R. Disorders of the gonads. In: Behrman RE, Kliegman RM, Jenson HB, editors. Nelson textbook of pediatrics. $16^{\text {th }} \mathrm{ed}$. Philadelphia: WB Saunders; 2000. p. 1744-66.

4. Andon M, Friedman SC. Ambiguous genitalia, micropenis, hypospadias, and cryptorchidism. In: Lifshitz $\mathrm{F}$, editor. A clinical guide. Pediatric endocrinology. $3^{\text {rd }}$ ed. New York: Marcel Dekker; 1996. p. 281-303.

5. Cai LQ, Zhu YS, Katz MD, Herrera C, Baez J, DeFilloRicart M, et al. $5 \alpha$-reductase-2 gene mutations in The Dominican Republic. J Clin Endocr Metab 1996; 81:1730-5.

6. Can S, Zhu YS, Cai LQ, Ling Q, Katz MD, Akgun S, et al. The identification of $5 \alpha$-reductase- 2 and $17 \beta$ hydroxysteroid dehydrogenase -3 gene defects in male pseudohermaphrodites from a Turkish kindred. J Clin Endocr Metab 1998; 83:560-9.

7. Imperato-McGinley J, Miller M, Wilson JD, Peterson RE, Shackleton C, Gajdusek DC. A cluster of male pseudohermaphrodites with 5-alpha-reductase deficiency in Papua New Guinea [abstract]. Clin Endocr 1991;34:293-8.

8. Urological Sciences Research Foundation. The 'Guevedoces' of the Dominican Republic. 2002 July 22. Available from: URL: http://www.USRF.org/news/ 010308-guevedoces.html

9. Brook CGD. A guide to the practice of paediatric endocrinology. $1^{\text {st }}$ ed. Cambridge: Cambridge University Press; 1993. p. 1-17.

10. Warne GL, Zajac JD. Disorders of sexual differentiation. Endocr Metab Clin J 1998;27:945-67.

11. Anhalt H, Neely EK, Hintz RL. Ambiguous genitalia. Pediatr Rev 1996;17:213-20.

12. Boehmer ALM, Brinkmann AO, Nijman RM, VerleunMooijman MCT, Ruiter PD, Niermeijer MF, et al. Phenotypic variation in a family with partial androgen insensitivity syndrome explained by differences in $5 \mathrm{a}$ dihydrotestosterone availability. J Clin Endocr Metab 2001;86:1240-6.

13. Hochberg Z, Chayen R, Reiss N, Falik Z, Makler A, Munichor $\mathrm{M}$, et al. Clinical, biochemical, and genetic findings in a large pedigree of male and female patients with 5-alpha-reductase 2 deficiency. J Clin Endocr Metab 1996;81:2821-7. 


\section{Paediatrica Indonesiana}

14. Kalantaridou SN, Chrousos GP. The impact of the human genome on endocrinology: special features. J Clin Endocr Metab 2002;87:2481-94.

15. Thigpen AE, Davis DL, Gautier T, ImperatoMcGinley J, Russell DW. The molecular basis of steroid 5-alpha-reductase 2 deficiency in a large Dominican kindred. New Eng J Med 1992;327:1216-9.

16. Boudon C, Lumbroso S, Lobaccaro JM, SzarrasCzapnik M, Romer TE, Garandeau P. Molecular study of the 5-alpha-reductase type 2 gene in three European families with 5-alpha-reductase deficiency. J Clin Endocr Metab 1995;80:2149-53.

17. Nordenskjold A, Ivarsson SA. Molecular characterization of $5 \alpha$-reductase type 2 deficiency and fertility in a Swedish family. J Clin Endocr Metab 1998;83:3236-8.

18. Achermann JC, Ozisik G, Meeks JJ, Jameson JL. Genetic causes of human reproductive disease. J Clin Endocr Metab 2002;87:2447-54.

19. Chavez B, Valdez E, Vilchis F. Uniparental disomy in steroid 5-alpha-reductase 2 deficiency. J Clin Endocr Metab 2000;85:3147-50.

20. Imperato-McGinley J, Gautier T, Pichardo M, Shackleton C. The diagnosis of $5 \alpha$-reductase deficiency in infancy. J Clin Endocr Metab 1986;63:1313-8.

21. Hiort O, Sinnecker GHG, Willenberg H, Lehners A, Zollner A, Struve D. Nonisotop single strand conformation analysis of the 5-alpha-reductase type 2 gene for the diagnosis of 5-alpha-reductase deficiency. J Clin Endocr Metab 1996;81:3415-9.

22. Honour JW, Savage MO. Testicular endocrine function. In: Ranke MB, editor. Diagnostics of endocrine function in children and adolescents. 2nd ed. Leipzig: Johann Ambrosius Barth Verlag; 1996. p. 314-25.

23. Mendonca BB, Inacio M, Costa EM, Arnhold IJ, Silva FA, Nicolau W, et al. Male pseudohermaphroditism due to steroid 5 alpha-reductase 2 deficiency: diagnosis, psychological evaluation, and management. Medicine 1996;75:64-76.

24. Meyer-Bahlburg HFL. Gender assignment and reassignment in 46,XY pseudohermaphroditism and related conditions. J Clin Endocr Metab 1999;84:3455-8.

25. Van Wyk JJ, Calikoglu AS. Should boys with micropenis be reared as girls? J Pediatr 1999;134:537-8.

26. Price P, Wass JAH, Griffin JE, Leshin M, Savage MO, Large DM, et al. High dose androgen therapy in male pseudohermaphroditism due to 5-alpha-reductase deficiency and disorders of the androgen receptor. J Clin Invest 1984;74:1496-508.

27. Cai LQ, Fratianni CM, Gautier T, Imperato-McGinley J. Dihydrotestosteronee regulation of semen in male pseudohermaphroditism with $5 \alpha$-reductase deficiency. J Clin Endocrinol Metab 1994;79:409-14.

28. Katz MD, Kligman I, Cai LQ, Zhu YS, Fratianni CM, Zervoudakis I, et al. Paternity in intrauterine insemination with sperm from a man with 5-alpha-reductase-2 deficiency. New Eng J Med 1997;336:994-7. 